\title{
A IMPORTÂNCIA DA PARTICIPAÇÃO E DO CONTROLE SOCIAL PARA A REPUBLIZAÇÃO DA ADMINISTRAÇÃO PÚBLICA BRASILEIRA
}

\section{Vitor Gabriel Garnica ${ }^{1}$ Marlene Kempfer ${ }^{2}$}

\section{Resumo:}

A pesquisa desenvolve o tema da reforma do Estado que tem seu marco constitucional com a Emenda $n^{\circ} 19 / 98$. Enfatiza os pilares da tradição republicana e a necessidade de construir meios de participação social para republicizar a gestão pública contemporânea do Brasil. Neste contexto aponta-se a importância das comissões, conselhos, audiências e consultas públicas e controles sociais que fortalecem a cláusula pétrea da democracia participativa. $\mathrm{O}$ percurso dos estudos considera método qualitativo a partir da doutrina e da legislação em vigor.

Palavras-Chaves: Estado Republicano; Participação Social; Reforma da Administração Pública; Decreto 9759/19; ADI 6121.

\section{THE IMPORTANCE OS PARTICIPATION AND SOCIAL CONTROL FOR THE REPUBLIC OF BRAZILIAN PUBLIC ADMINISTRATION}

\begin{abstract}
:
The research develops the theme of state reform that has its constitutional framework with Amendment No. 19/98. Emphasizes the pillars of the republican tradition and the need to build means of social participation to republish contemporary public management in Brazil. In this context, the importance of the committees, councils, hearings and public consultations and social controls that strengthen the stone clause of participatory democracy is pointed out. The course of studies considers a qualitative method based on the doctrine and legislation in force.
\end{abstract}

Keys-Words: Republican State; Social Participation; New Public Administration; Decree 9759/19; ADI 6121

\section{INTRODUÇÃO}

A pesquisa enfatiza a concepção do governo republicano e a defesa da necessidade contemporânea da republicização. Sugere que ao lado da democracia representativa possa haver espaço jurídico e político para a democracia participativa. Assim, além de promover um ambiente de diálogo tem-se meios para controle social.

\footnotetext{
${ }^{1}$ Mestrando do Programa de Direito Negocial da Universidade Estadual de Londrina. Bolsista pela CAPES. Endereço eletrônico: vitorgarnica@ hotmail.com. http://lattes.cnpq.br/5990451598884333

${ }^{2}$ Doutora e Mestre em Direito do Estado pela Pontifícia Universidade Católica de São Paulo (PUC/SP). Professor da graduação em Direito e do Programa de Mestrado em Direito Negocial da Universidade Estadual de Londrina. Endereço eletrônico: mkempferb@ gmail.com. http://lattes.cnpq.br/7141753184018389
} 
O percurso deste estudo considerou, primeiramente, a proposta brasileira de republicização trazida por meio da Emenda Constitucional 19/1998, a qual teve importante apoio do então Ministro da Administração Federal e da Reforma do Estado Luís Carlos Bresser-Pereira defendendo, especialmente, a implementação dos pilares da Reforma Gerencial.

Esta proposta traz em seu cerne que algumas atividades de competência do Estado e também permitidas para a sociedade civil pudessem ser descentralizadas ou quando promovidas pelo Estado sua gestão seja participativa. Na primeira hipótese é a atuação do Terceiro Setor seja por meio de ONG's, Organizações Sociais (Lei n 9.637) e Organizações Sociais de Interesse Público (Lei n ${ }^{\circ}$ 9.790). Na segunda hipótese, diante da atuação do Estado possibilitar a participação de representantes da sociedade civil no gerenciamento de políticas públicas de largo alcance social. Neste caso por meio de conselhos consultivos, as ouvidorias, as comissões e as consultas públicas que visam fortalecer a o princípio fundamental da participação social que possibilitam a republicização do Estado. A efetividade desta proposta de gestão pública depende, também, de mecanismos de controles internos e externos.

A atualidade e importância da pesquisa está a partir da constatação de que recentemente foi publicado o Decreto 9759/2019 que extingue conselhos consultivos e colegiados que existiam no controle da administração pública federal. Tal decisão de governo sinaliza um caminho contrário à ideia de republicizar dificultando avanços na democracia participativa.

Questões em torno da constitucionalidade deste decisão foram trazidas por meio da Ação Direta de Inconstitucionalidade de número 6121, foi protocolado em 16 de abril de 2019, impetrada pelo Partido dos Trabalhadores que defende a participação social como direito fundamental da soberania popular, além dos aspectos de incompetência legislativa por parte do Poder executivo, sendo matéria competente pelo Congresso Nacional, uma vez que diversos conselhos foram instituídos por força de Lei.

O percurso dos estudos considera método qualitativo a partir da doutrina e da legislação em vigor.

\section{A EMENDA CONSTITUCIONAL 19/98 E A PROPOSTA DO ESTADO REPUBLICANO}


É importante compreender o contexto no qual a Emenda Constitucional 19 de 1998 foi aprovada. O Estado brasileiro passava por uma reconfiguração desde a Constituição de 1988 e em 1990 avançava com o Programa Nacional de Desestatização. Foi um período de transições que tinham vários enfoques, entre eles, discussões sobre as atribuições não exclusivas e exclusivas do Estado contemporâneo em especialmente aquelas que atenderiam aos direitos fundamentais.

Redimensionar e qualificar o Estado para que fosse de fato efetivo em suas responsabilidades foi um aspecto essencial da Reforma da Administração Federal e Reforma do Estado, conforme Luís Carlos Bresser-Pereira (2009, p.148/153). Propunha um redirecionamento das atividades que pertencem ao Estado, ampliando a participação social para a consecução dos serviços públicos não-estatais (escolas, órgãos administrativos, hospitais) sob a forma jurídica de organizações sociais (fundações e associações). Por fim, propunha-se delimitar as atividades do Estado apenas naquelas que sejam essenciais ao interesse público e à máquina estatal, tal quais o controle econômico do Banco Central, previdência, serviços e obras de infraestrutura e os serviços sociais pertinentes a direitos humanos.

Defende o Prof. Bresser-Pereira (2009, p. 99) que há fatores exógenos e endógenos que devem ser considerados para avançar na proposta de Reforma da Gestão Pública. Sobre os exógenos cita alguns marcos dos quais fortificaram a ideia da remodelação do Estado, entre elas enumera os fatores políticos, literários e econômicos em um contexto de crescente globalização.

A respeito do fator político indica Bresser-Pereira (2009, p. 211) a posse de Margaret Thatcher (primeira Ministra da Inglaterra no período de 1979 a 1990) e de Ronald Reagan (presidente dos Estados Unidos em 1981 a 1989) que em seus mandatos implementaram a Reforma Administrativa, principalmente no que tange as atividades pertencentes ao Estado transferidas para terceiros. O historiador Eric Hobsbawn (2010, p.394) evidencia que durante o período da Era de Ouro os Estados foram capazes de acumular grande parte de capital até a crise de 1973, o que retardou essa mudança, começando esse novo modelo de Estado a ser implementado apenas no início da década de 80, tendo como justificativa os altos gastos do Estado e necessidade de política de austeridade que foi implementada e conduzida em seus mandatos. 
No aspecto literário vale ressaltar a contribuição dos neoliberais como Robert Nozick e Milton Friedman que compunham em suas teses a defesa plena no mercado para promover o bem-estar, contrastando o Estado de Bem-Estar ou do Estado social-democrático até então vigente (BRESSER-PEREIRA, 2009, cap. 9). Outro marco teórico importante dentro do aspecto da Gestão Público foi engendrado pelos escritores David Osborne e Ted Gaebler em 1992, ambos os autores teorizam e caracterizam as políticas iniciadas pelos novos governos (Reagan e Thatcher) a fim de sistematizar a reformas da gestão pública e redefinir as competências do Estado (OSBORNE; GAEBLER, 1994, pgs. 2-5), na obra intitulado "Reinventing government", em que sugere a redistribuição de tarefas do estado para a sociedade civil e para as empresas tendo em vista a eficiência da máquina pública e a redução de custos do Estado.

Dentre os fatores exógenos, o mais importante é a globalização. O contexto mundial evidenciava a nova proposta de Gestão Pública defendida por países tais quais a Austrália, Nova Zelândia, França, Estados Unidos da América, Suécia (BRESSER-PEREIRA, 2009, p. 227-238), empenhados em promover, sobretudo, a descentralização, a delegação e republicização de diversos setores e órgãos do Estado. Além dos diversos países que compunham a reforma administrativa em sua agenda:

\begin{abstract}
Após a crise econômica mundial dos anos 70, das duas crises do petróleo, o Estado de bem-estar, que fora implementado com os excedentes da produção desse período, provedor de direitos sociais numa fase de crescimento da economia capitalista no mundo, deu lugar a um quadro de crescimento e ineficácia das antigas estruturas. Várias causas foram apontadas para justificar essa ineficiência, como a súbita alteração da dinâmica financeira e a incapacidade das instituições de adaptar-se ao acelerado ritmo de transformação social e econômica. Independente da causa, no entanto, predominava a idéia de que não era mais possível manter a equação que relacionava economia, política e direito nos mesmos termos que no período dos trinta anos do pós-guerra. (TOJAL, 2002, p. 153)
\end{abstract}

Em âmbito mundial, a transição do Estado Social Democrático para o Estado SocialLiberal era uma realidade global, no qual o Brasil, mesmo que tardiamente veio a conduzir tal reforma em 1998.

Os fatores endógenos são ilustrado por Bresser-Pereira (2009, p. 211) seriam: a crise fiscal; a ineficiência dos serviços prestados somados a má qualidade em sua execução e; a burocracia patrimonialista da administração pública brasileira. 
Em relação a crise fiscal, a aplicação das teses do Estado Keynesiano, em escala global, aprofundou os gastos do Estado e as consequências indicam grave déficit orçamentário durante os anos no qual este modelo foi predominante.

O Brasil não escapou da crise mundial conforme aponta o então Presidente Fernando Henrique Cardoso (1995) nas páginas introdutórias do Plano Diretor da Reforma do Aparelho do Estado:

\begin{abstract}
A crise brasileira da última década foi também uma crise do Estado. Em razão do modelo de desenvolvimento que Governos anteriores adotaram, o Estado desviou-se de suas funções básicas para ampliar sua presença no setor produtivo, o que acarretou, além da gradual deterioração dos serviços públicos, a que recorre, em particular, a parcela menos favorecida da população, o agravamento da crise fiscal e, por consequiência, da inflação. Nesse sentido, a reforma do Estado passou a ser instrumento indispensável para consolidar a estabilização e assegurar o crescimento sustentado da economia. (BRASIL, 1995, p.6)
\end{abstract}

Aliado a essa lógica de âmbito global, a insatisfação da prestação de serviços e o alto custo para a execução das atividades geridas pelo Estado foi outro fator determinante para uma nova releitura da Administração Pública, no qual busca-se incluir a participação social para a republicização do Estado:

A montagem de uma estrutura administrativa que enfatizasse os procedimentos gerenciais em prol da melhoria da qualidade dos serviços prestados, a incessante busca pela eficiência e pela redução de custos na prestação de serviços públicos e o estimulo à participação popular representam, pelo menos no aspecto formal, os pontos norteadores da reforma administrativa, iniciada na última década do século XX. (KEMPFER; VELOSO, 2008, p. 1170)

A necessidade de mudança da Administração Pública Burocrática para a Gestão Pública Gerencial se fez necessária uma vez que a burocracia vigente estava aliada aos ideais do patrimonialismo consolidado em nossas veias históricas:

[...]O patrimonialismo pessoal se converte em patrimonialismo estatal, que adota o mercantilismo como a técnica de operação da economia. Daí se arma o capitalismo político, ou capitalismo politicamente orientado, não calculável nas suas operações, em terminologia adotada no curso deste trabalho. A compatibilidade do moderno capitalismo com esse quadro tradicional, equivocadamente identificado ao pré-capitalismo, é uma das chaves da compreensão do fenômeno histórico português-brasileiro, ao longo de muitos séculos de assédio do núcleo ativo e expansivo da economia mundial, centrado em mercados condutores, numa pressão de fora para 
dentro. Ao contrário, o mundo feudal, fechado por essência, não resiste ao impacto, quebrando-se internamente, para se satelitizar, desfigurado, ao sistema solar do moderno capitalismo. Capaz de comerciar, exportando e importando, ele adquire feição especulativa mesmo nas suas expressões nominalmente industriais, forçando a centralização do comando econômico num quadro dirigente. Enquanto o sistema feudal separa-se do capitalismo, enrijecendo-se antes de partir-se, o patrimonialismo se amolda às transições, às mudanças, em caráter flexivelmente estabilizador do modelo externo, concentrando no corpo estatal os mecanismos de intermediação, com suas manipulações financeiras, monopolistas, de concessão pública de atividade, de controle do crédito, de consumo, de produção privilegiada, numa gama que vai da gestão direta à regulamentação material da economia. (FAORO, 2008, p. 871)

Expostos os motivos exógenos e endógenos que foram os maiores propulsores para a Reforma da Administração Pública fica explicito da necessidade do Estado caminhar para o objetivo de reconfigurar. As soluções passam por privatizações, concessões, descentralizações e desconcentrações, delegações que fazem parte das principais políticas do Brasil a partir da década de 90, a fim de assegurar melhor eficiência a máquina estatal.

Além dos fatores que contextualizam a proposta de reforma do estado brasileiro apresentados, a republicização é uma tarefa árdua pois exige transparência e instrumentos para efetivar a participação social como direito fundamental. Para alcançar tais objetivos temse amparo no atual texto constitucional tais quais o art. 37 quanto à eficiência e o direito de

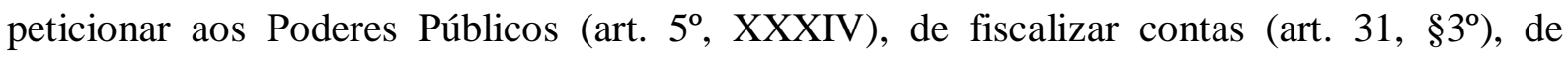
denunciar irregularidades ou ilegalidades $\left(\operatorname{art} .74, \S 2^{\circ}\right.$ ), participação dos conselhos de gestão (art. 198, III; art. 204, II; art. 206, VI), entre outros, quanto às possibilidades de participação social.

\section{A PARTICIPAÇÃO, INFORMACAO E O CONTROLE SOCIAL: PILARES DA REPUBLICIZAÇÃO DO ESTADO BRASILEIRO}

A Emenda Constitucional 19/98 possibilita a efetivação do Estado Republicano em alternativa ao modelo patrimonialista e burocrático que ainda tem suas raízes na gestão pública brasileira. Diante de tal conjectura uma democracia apenas poderá fortalecer-se quando sejam positivados e garantidos os direitos da participação popular, seja por meio da 
participação indireta (representativa) e participação direta (atuação e fiscalização), conforme a própria ideia inicial do constituinte de 1988 (SILVA, 2004, p. 69).

Neste contexto destaque-se os ideais da liberdade positiva republicana, teoria acolhida pelo nosso legislador, ao definir as diretrizes do Estado Republicano e a consequente Crise da Democracia Representativa a reafirmar a necessidade da consolidação da participação direta e do controle social. Portanto, deve a Administração Pública conceder e incentivar os meios necessários para a consolidação dos preceitos fundamentais da participação social, tal como a transparência dos atos administrativos tendo como objetivo finalístico o fortalecendo dos meios de controle social, utilizando-se das consultas públicas, audiências ou sessões públicas, as ouvidorias e os conselhos ou colegiados como meios eficazes para a consolidação deste.

O Professor Floriano Peixoto de Azevedo Marques Neto (2002, p. 133-143) expõe a transição e o fim da dicotomia entre o direito público e o privado. Segundo o autor, a superação dessa dualidade deve-se, sobretudo, a constante necessidade da utilização dos instrumentos disponíveis em ambas as esferas. Portanto, o diálogo entre Estado e sociedade civil deve perpassar de forma crescente para a resolução de conflitos. Em linhas gerais, essa conjectura está posta e não há como evitá-la. A globalização e a insatisfação com o poder político central consolidam a afirmação da necessidade do trabalho mútuo entre Estado e Sociedade.

Outro fator importante para o debate é a escolha da liberdade positiva republicana. $\mathrm{O}$ professor Cesar Augusto Ramos (2011, p. 51-57) traz a discussão sobre o modelo liberal e o republicano de liberdade. Observa-se em sua contribuição a este estudo, a superação do conceito de liberdade negativa e abre os horizontes para a compreensão de um novo conceito da liberdade, a republicana, na qual compatibiliza com os novos anseios do Estado Contemporâneo, tal qual a participação social e o dever de agir do cidadão, com responsabilidade e fiscalização da res publica.

Assim, diante de uma sociedade complexa, a importância da liberdade em seu caráter subjetivo deve ser ampliado e conciliada a uma abordagem subjetiva e intersubjetiva:

Os Estados livres, como as pessoas, são definidos pela capacidade de autogoverno realizada no espaço público, no qual os cidadãos se qualificam para a vida política como indivíduos dotados de virtudes cívicas. O mote republicano de que o preço da liberdade é a eterna vigilância exige uma política virtuosa que os indivíduos, como governantes e governados, 
desenvolvem na coletividade, no sentido de exercer ações e de perseguir fins em prol do bem público. (RAMOS, 2011, p. 64)

Os argumentos do fim da dicotomia entre público e privado e o da escolha de liberdade republicana, permitem a aproximação com a res publica. Portanto, é importante a decisão do indivíduo em participar mais ativamente e conjuntamente das escolhas públicas. Assim, elucida-se que:

Os principais fatores da crise encontra-se: (a) nos sucessivos descumprimentos dos programas; (b) no fenômeno da corrupção da classe política; (c) no declínio de vastos setores sociais; (d) na complexidade das demandas e na especialização técnica; (e) na crise dos grandes discursos de legitimação e, finalmente, (f) na influência dos meios de comunicação. (WOLKMER, 2001, p. 87)

Neste contexto da realidade é fundamental enaltecer todas as possibilidades para implementar a Democracia Participativa. Este é também um dos traçados apontados diante do tema da Administração Pública e a nova Gestão de Governo Gerencial que propõe participação ativa e fiscalizatória da sociedade civil aos interesses da res publica (BRESSERPEREIRA, 2009, p. 301).

Para tal realização é importante a transparência pois por meio dela é que se torna viável a participação e o controle social. A transparência e a informação são direitos subjetivos de todos cidadãos, uma vez que possibilitam o conhecimento para escolhas e tornam o indivíduo um ser autônomo e consciente para as tomar decisões no que concerne ao ambiente no qual vive e participa (KEMPFER, 2016, p. 192).

Importante destacar, portanto, que a Lei do Acesso a Informação ${ }^{3}$ (Lei no 12.527/11) garante a procedimentalização para que cidadãs e cidadãos e os órgãos estatais se relacionem conforme pilares republicanos e democráticos e possibilitam os instrumentos jurídicos para o controle social.

Tem-se previsão de outras possibilidades de participação e controle da sociedade como interesses do indivíduo a res publica, entre elas:

i) as consultas públicas que podem ser utilizadas por todos os Entes Federativos, como também na Administração Pública direta e indireta, conforme dispõe o Art.29 da Lei de Introdução do Código Civil (Lei n ${ }^{\circ} 4.657 / 42$ ), ao dispor que qualquer órgão público na edição

\footnotetext{
${ }^{3}$ Art. $1^{\circ}$ Esta Lei dispõe sobre os procedimentos a serem observados pela União, Estados, Distrito Federal e Municípios, com o fim de garantir o acesso a informações previsto no inciso XXXIII do art. $5^{\circ}$, no inciso II do $\S$ $\underline{3^{\circ} \text { do art. } 37 \text { e no } \$ 2^{\circ} \text { do art. } 216 \text { da Constituição Federal. }}$
} 
de atos normativos deverá ser precedida de consulta pública para a manifestação e participação pública. Por meio deste instrumento o distanciamento entre o cidadão e o Estado são atenuados, além que permite a antecipação do problema ao aplicar a norma sem o aceite popular. Deste modo, são instrumento fundamentais para reforçar a participação do cidadão ao processo decisório (AMARAL; CID, 2012, p. 4). O Decreto 9.191 de 2017, ao dispor sobre o procedimento submetida por meio de consulta pública ao Poder Executivo para a elaboração de ato normativo, conforme consta em seus artigos 40 ao 43. Deste modo, qualquer cidadão ao propor uma ideia, tendo grande alcance popular por meio da consulta pública, sendo posteriormente ser apreciada pela Casa Civil.

ii) as audiências ou sessões públicas, regidas no Art. 58, §2, inciso II, da Constituição Federal, ao dispor sobre a realização de audiências públicas com entidades da sociedade civil. Trata-se de um chamamento à sociedade civil para possibilitar a participação de modo a contribuir em temáticas que serão objeto de regramento a conduzir condutas na sociedade. A importância desta participação desta o Código de Processo Civil (Lei n ${ }^{\circ}$ 13.105/2015) em seu Art. 138 ao tratar sobre o amicus curiae ("amigo da corte"),

iii) os órgãos de ouvidorias, nos termos da Lei ${ }^{\circ} 13.460$ de 2017, dispõe sobre a participação, proteção e defesa dos usuários dos serviços públicos da Administração Pública. Em seu art. 13 prevê a utilização das Ouvidorias para proteger e fiscalizar a administração pública, além de acompanhar e receber as denúncias do usuário. Assim, também, a Lei no 13.848 de 2019 que impõe a existência de um ouvidor do qual regulamenta a presença de ouvidorias independentes do setor da atividade econômica para zelar e apurar possíveis denúncias sobre as atividades das agências. Portanto, busca a democracia participativa e a mediação de conflitos, refletindo sobre a consciência crítica do órgão e gerando eficiência ao órgão (ANVISA, 2019);

iv) os órgãos de conselhos consultivos, espaço utilizado para a participação direta da sociedade civil nos órgãos da Administração Pública, são regidos por legislação constituída pela União, pelos estados e pelos municípios. A constituição Federal ao dispor sobre os instrumentos de participação social, prevê em seu art. 29, inciso VII, a cooperação das associações representativas no planejamento social municipal. Assim, o CONAMA (Lei $\mathbf{n}^{\circ}$ 6.938/81), o Conselho Nacional de Saúde (CNS - Lei nº 8.142/90) e tantas outras instituídas por lei e possuem função social essencial na efetividade e fiscalização das respectivas áreas. 
Assim, possuem as funções de formular, supervisionar e avaliar políticas públicas (VILELA, 2005, p. 4).

Dentro do contexto da Reforma da Gestão Pública, as agências reguladoras foram um avanço na Administração Pública Indireta no que tange a atividade regulatória e a Reforma Gerencial. Um exemplo que contenha os instrumentos da participação social pode ser ilustrado pela ANVISA (2019). Visando estabelecer boas práticas de governança como também utilizar de suas prerrogativas para consolidar a participação social, o endereço eletrônico da Anvisa permite o acesso as consultas públicas, como a realização das audiências públicas, as ouvidorias, além de disponibilizar o acesso as informações sobre as políticas regulatórias e o convite (explicando os mecanismos e instrumentos) para o debate público.

A importância de tais instrumentos jurídicos aliado ao direito da participação e do controle social caminham para consolidar não somente a democracia representativa mas, especialmente, a democracia que ouve os destinatários diretos da atuação do Estado. Assim, crescem as possibilidades de atuação estatal eficiente e transparente. Escolhas governamentais que andam em direção contrária, defende-se, são ilegais e inconstitucionais.

\section{AMEAÇAS AOS PILARES DA REPUBLICIZAÇÃO: CONTROLE DAS INFORMAÇÕES E DIMINUIR AS POSSIBILIDADES DE DECISOES COLEGIADAS COM PARTICIPACAO POPULAR DIRETA}

A presença de instrumentos que disponibilizem a possibilidade da sociedade civil agir é direito fundamental, assim, há de falar sobre os meios que ampliam o Acesso à Informação e ao controle da administração pública, conforme preceitua o inciso XXXIII do Art. $5^{\circ}$ e, também, no inciso II, $\$ 3^{\circ}$ do Art. 37, ambos da Constituição Federal de 1988. Porém, o Decreto 9.690 assinado pelo Vice-Presidente, Antônio Hamilton Martins Mourão, em 23 de janeiro de 2019 anuncia medidas que ameaçam os pilares do Estado Republicano em desrespeito ao Art. 27 da Lei de Acesso à Informação (Lei n ${ }^{\circ}$ 12.527/12). Este ato administrativo amplia o número de pessoas que possam dispor sobre a classificação do sigilo dos documentos da administração pública, competência esta que fora reservada para ocupantes de cargos de outros níveis, de maior hierarquia, de decisão do Poder Executivo.

Além desta iniciativa tem-se o Decreto 9.759 de 11 de abril de 2019 que extingue e estabelece diretrizes, regras e limitações para colegiados da administração pública federal. 
Assim, o referido decreto tem por via de regra a extinção dos colegiados da administração públicas federal, excetos os previstos no regime interno ou no estatuto de instituição federal de ensino e os criados após de $1^{\circ}$ de janeiro de 2019 (art. 5º. Estes órgãos são pilares da democracia participativa que levam à republicização. Ao extinguir conselhos dificultam-se as possibilidades da participação direta e do controle público, ferindo, sobretudo, as possibilidades democráticas da soberania popular.

\subsection{Ameaças aos pilares da republicização: o controle das informações}

A Emenda Constitucional $n^{\circ}$ 19/98 além de redefinir as atividades concedidas pelo Estado, introduziu as técnicas da atividade empresarial na busca da profissionalização dos servidores. A transparência é de suma importância para a construção de uma boa governança e para a efetivação do Estado Republicano. Por meio dela possibilita-se escolha pública e controle social. Para o exercício deste direito deve-se garantir o acesso à informação. Portanto, o cidadão só poderá exercer o seu direito de informação (passivamente ou ativamente), se o órgão agir no seu dever de informar (KEMPFER, 2016, p. 194).

Na contramão desta nova concepção do dever agir da Administração Pública, o atual Poder Executivo publicou o Decreto $\mathrm{n}^{\circ} 9.690$ em 23 de janeiro de 2019, por meio do qual delega a competência de classificação de documentos para o grau ultrassecreto (Art. 30, § $1^{\circ}$, $2^{\circ}$ ) para servidores ocupantes de cargos de comissão. Isso reflete a incompatibilidade aos preceitos da transparência enunciadas pela Lei de Acesso à Informação (Lei no 12.527 de 2011) no qual dispõe em seu art. 27, que apenas os cargos de Presidente e Vice-Presidente da República, Ministros do Estado, os Comandantes das Forças Armadas e os Chefes de Missões Diplomáticas e Consulares poderiam utilizar de tal prerrogativa. A abrangência da nova norma de competência prestigia servidores de governo que tem um vínculo precário com o Estado, uma vez que são de livre indicação e demissão.

Outro aspecto importante a ser ressaltado, foi a ausência de diálogos com os órgãos relacionados na proteção da transparência na Administração Pública, conforme o caso de Manoel Galdino, diretor executivo do Transparência Brasil. Neste sentido também a manifestação de Gil Castello Branco, secretário-geral da Associação Contas Abertas, alegando que a transparência era a regra, enquanto o sigilo, a exceção (HESSEL, 2019, n.p.). 
Deste modo, constata-se a atitude antidemocrática e despótica do Poder Executivo ao editar este ato normativo.

Em face destes evidentes argumentos o governo admitiu o erro e recuou ao revogar o Decreto 9.690/19 por meio do Decreto $n^{\circ}$ 9.716/19, restabelecendo as competências da Lei de Acesso à Informação, impedindo a classificação de documentos sigilosos a não ser pelas autoridades mencionadas no Art. 27 (LIDNDER; RIBEIRO, 2019). Este estado de alerta das instituições e da sociedade civil são fundamentais para preservar um dos pilares do Estado Republicano que é a transparência na gestão pública.

\subsection{Ameaças aos pilares da republicização: diminuir as possibilidades de decisões colegiadas com participação popular direta}

Outro fator para a consolidação do Estado Republicano é viabilizar a democracia direta que exige a participação social. Deste modo, os colegiados e os conselhos consultivos foram a opção do legislador para oportunizar a fiscalização, encaminhamento de políticas publicas, formular e definir planos de ações conjuntamente com a administração pública.

Estes importantes pilares foram desconsiderados pelo Governo Federal quando publicou o Decreto $\mathrm{n}^{\circ} 9.759$ em 11 de abril de 2019, por meio do qual extingue diversos conselhos consultivos que compõem a administração pública federal. Em face desta realidade jurídico-política foi proposta a Ação Direta de Inconstitucionalidade de $\mathrm{n}^{\circ} 6.121$ em 16 de abril de 2019, pelo Partido dos Trabalhadores. Os argumentos constantes na ADI indicam uma direta afronta ao Princípio da Soberania Popular e ao Princípio da Legalidade.

\subsubsection{Do Decreto no 9.759 de 2019}

O presente artigo pretende elucidar sucintamente sobre os últimos eventos e as devidas argumentações de cada sujeito no que concerne sobre esse debate. Primeiramente, o Poder Executivo utilizando sobre as prerrogativas do "enxugamento" da máquina pública e na melhor efetividade e contenção de gastos da Administração Pública propôs o ato normativo em questão (PONTES, 2019). 
. O decreto "extingue e estabelece diretrizes e regras e limitações para colegiados da administração pública federal", a fim de elucidar os efeitos jurídicos-administrativos, o seguinte ato normativo define colegiados:

Art. $2^{\circ}$. Para os fins do disposto neste Decreto, inclui-se no conceito de colegiado:

I - conselhos; II - comitês; III - comissões; IV - grupos; V - juntas; VI equipes; VII - mesas; VIII - fóruns; IX - salas; e X - qualquer outra denominação dada ao colegiado.

Parágrafo único. Não se incluem no conceito de colegiado de que trata o caput:

I - as diretorias colegiadas de autarquias e fundações;

II - as comissões de sindicância e de processo disciplinar; e

III - as comissões de licitação-

A proposta para este rol taxativo da administração pública inclui diretrizes, regras e limitações sobre os colegiados. Tais quais a restrição da criação de outros sub-colegiados, além de dispor sobre novas regras para a criação destes.

Porém o aspecto mais marcante e passível de controversas é sobre a extinção discriminada disposta no decreto. Assim, o Governo Federal propõe a extinção dos colegiados via de regra e apenas preservou os colegiados previsto no regime interno ou no estatuto de instituição federal de ensino e os colegiados criados a partir de $1^{\circ}$ de janeiro de 2019 (art. $5^{\circ}$ ). Segundo o levantamento realizado pela Procuradoria Geral da República seriam extintos mais de 700 colegiados, por exemplo: o Comitê Gestor da Internet no Brasil e o Conselho Nacional de Enfrentamento ao Tráfico de Pessoas (PONTES, 2019).

\subsubsection{Da Ação Direta de Inconstitucionalidade $n^{0} 6.121$ de 2019}

Diante de tal situação, o Partido dos Trabalhadores impetrou Ação Direta de Inconstitucionalidade ( $\mathrm{n}^{\circ}$ 6.121) na data de 15 de Abril de 2019. A ação previa a ilegalidade do ato do Poder Executivo pelos art. 48, inciso $\mathrm{XI}^{4} ; 84$, inciso VI, alínea a ${ }^{5}$ e; $88^{6}$, todos da Constituição Federal de 1988. Relativo a esses Artigos, o ADI revela a nítida

\footnotetext{
${ }^{4}$ Art. 48. Cabe ao Congresso Nacional, com a sanção do Presidente da República, não exigida esta para o especificado nos arts. 49, 51 e 52, dispor sobre todas as matérias de competência da União, especialmente sobre: XI - criação e extinção de Ministérios e órgãos da administração pública;

${ }^{5}$ Art. 84. Compete privativamente ao Presidente da República:

VI - dispor, mediante decreto, sobre:

a) organização e funcionamento da administração federal, quando não implicar aumento de despesa nem criação ou extinção de órgãos públicos;

${ }^{6}$ Art. 88. A lei disporá sobre a criação e extinção de Ministérios e órgãos da administração pública.
} 
inconstitucionalidade da competência do Poder Executivo, uma vez que não pode o Presidente da República por meio de suas atribuições extinguir ministérios e órgãos da Administração Pública, revelando uma afronta ao Princípio da Separação de Poderes, uma vez que esta competência é do Congresso Nacional e a extinção de colegiados instituídos por lei só poderiam ser feitos pelo mesmo tipo normativo (FEDERAL, 2019).

Outro argumento (“Da violação do princípio da participação popular”) utilizado na ADI vai de encontro ao pressupostos expostos neste Artigo, a participação Popular. Assim, também a Constituição Federal dispõe em seu art. $10^{7}$. O autor da ADI argumenta sobre a mudança de paradigma da administração pública contemporânea e a necessidade do fortalecimento da aproximação entre administração federal e a população. Também, o autor da ação pontua alguns colegiados extremamente importantes para a fiscalização e a busca de resultados para os problemas no Brasil, tais quais: o Conselho de Recurso do Sistema Financeiro Nacional, Comissão Interministerial de Governança, a Comissão Nacional da Biodiversidade e Comissão Nacional de Desenvolvimento Sustentável dos Povos e Comunidades Tradicionais, a Comissão Nacional para Erradicação do Trabalho Escravo (STF, 2019).

É inegável a contribuição desses colegiados para a efetivação do Estado Republicano, sendo ela potencializada e, muitas vezes, efetivadas através desses colegiados que o Decreto busca extinguir. Suprimir a existência dos conselhos é minar a efetividade da participação social e, corresponde, a um retrocesso visível.

\subsubsection{Da Liminar e do Deferimento Parcial do Supremo Tribunal Federal}

A ADI 6.121 foi então recebida pelo Ministro e Relator Marco Aurélio Collor e em 23 de abril de 2019 concedeu a liminar da Ação Direta de Inconstitucionalidade por decisão monocrática por causa do art. $5^{\circ}$ do Decreto, indo para plenário posteriormente.

Em plenário a ADI foi deferido parcialmente, por 6 (seis) votos a 5(cinco), mantendo o entendimento do Relator Marco Aurélio (em 28 de junho de 2019). No que tange a discussão e objeto deste artigo, o plenário dividiu-se sobre a integralidade da Ação, da qual os

\footnotetext{
${ }^{7}$ Art. 10. É assegurada a participação dos trabalhadores e empregadores nos colegiados dos órgãos públicos em que seus interesses profissionais ou previdenciários sejam objeto de discussão e deliberação.
} 
ministros Luís Roberto Barroso, Edson Fachin, Rosa Weber, Carmen Lucia e Celso de Mello defendiam a Inicial. Vale salientar a fala do Ministro Barroso (FEDERAL, 2019):

Acho que o presidente não só pode como deve extinguir conselhos desnecessários, onerosos, inoperantes e desnecessários, mas que extinguir todos, inclusive os que têm papel fundamental, para se atingir os que são desnecessários, é medida excessiva.

Porém, os demais ministros discordando e acolhendo, exclusivamente, a Inconstitucionalidade da Incompetência Legislativa por parte do Poder Executivo optaram por decidir que o Decreto não poderia extinguir Colegiados que tivessem sua origem por Lei, apenas podendo o Presidente da República dispor sobre os colegiados que foram instaurados por ato normativo igual ou inferior ao de Decreto.

Portanto, a maioria do plenário (seis ministros) entendeu que o Presidente da República tem a competência em extinguir os órgãos da administração federal que estão dispostos em decretos ou atos normativos que não sejam Lei. Assim, o Decreto $\mathrm{n}^{\circ} 9.812$ de 2019 é uma republicação do Decreto ora estudado com as devidas alterações discutidas pelo Supremo Tribunal Federal.

Conforme o desejo do Governo Federal foram extintos 734 de colegiados após a publicação do decreto em 28 de Junho de 2019 (MAIA; ALEIXO; SACONI, 2019). Porém o anuncio de tais políticas não impactam bem para quem vislumbra um Estado mais transparente e republicano.

\section{CONSIDERAÇÕES FINAIS}

A emenda constitucional no 19 de 1998 traz possibilidades jurídico-políticas para realizar a republicização do Estado. Entre os pilares do republicanismo destaque-se a participação e o controle social que são os norteadores desta nova reconfiguração do Estado. Os pressupostos da transparência aliados aos instrumentos que trazem efetividade ao controle social são de fundamental importância para a boa execução dos serviços públicos e promover 
a cidadania. A consequência destas escolhas e efetiva implementação será o fortalecimento da democracia participativa que pode caminhar ao lado da democracia representativa.

Os caminhos para alcançar tais objetivos foram indicados na pesquisa como sendo o amplo acesso à informação ao consolidar o direito subjetivo de escolha ao cidadão em exercer a sua cidadania e o republicanismo. Por meio da informação, a escolha do republicanismo baseia-se no cuidado da res publica, sendo esta exercida por meio das consultas públicas, das audiências ou sessões públicas, também as ouvidorias são utilizadas a fim de dirimir conflitos e auxiliar os setores por ela tutelados e, por fim, os conselhos consultivos que garantem a efetividade na consolidação do Estado Republicano.

Recentemente, pode-se indicar, que tais pilares foram ameaçados quando foram publicados no início deste ano os decreto de nº 9.690 e 9.759, o primeiro dispondo sobre a Lei de Acesso à Informação, aumentando os indivíduos que poderiam classificar documentos como sigilosos (afetando diretamente na transparência dos órgãos públicos) e o segundo do qual dispõe sobre a extinção de diversos conselhos consultivos, estes que garantem e preconizam o Estado Republicano. Deste modo, a revogação do art. $5^{\circ}$ do Decreto $n^{\circ}$ 9.690/2019 e, também, a decisão do STF em restringir a extinção de diversos colegiados da administração pública federal demonstram a ameaça que tais dispositivos trazem à transparência (e ao Direito a Informação) e, também, à participação e ao controle social elucidados como essenciais para a configuração das virtudes cívicas e do Estado Republicano.

Portanto, não nos resta dúvidas que a edificação do diálogo entre sociedade civil e Estado devem estar assentados sobre o maior acesso à Informação, do qual a Administração Pública utiliza-se da transparência como meio mais efetivo para o controle social. Ao lado disso, a republicização é efetivada quando os instrumentos de participação social são utilizados pela sociedade civil. Apenas quando firmados estes pilares a democracia participativa será consolidada pelo diálogo constante entre os administradores/políticos e população e, deste modo, fortalecendo a democracia representativa ao passo da construção do Estado Republicano.

\section{REFERÊNCIAS BIBLIOGRÁFICAS}

AMARAL, João; CID, Nélia Monte. Consulta pública no Processo Legislativo

Parlamentar: Coleção Direito Parlamentar. 2012. ISBN: 978-972-556-606-0. Disponível em: 
$<$ https://www.parlamento.pt/ArquivoDocumentacao/Documents/Consulta_publicaProcessoLe gislativoParlamentar.pdf $>$ Acesso em: 01 set. 2019

ANVISA. Agência Nacional de Vigilância Sanitária. 2019. Disponível em:< http://portal.anvisa.gov.br/ouvidoria>. Acesso em: 01 set. 2019

BARROSO, Luis Roberto Barroso. Curso de direito constitucional contemporâneo: os fundamentos constitucionais e a Constituição do novo modelo. São Paulo: Saraiva. 2009.

BRESSER-PEREIRA, Luiz Carlos. Reforma do Estado e Administração Pública Gerencial. Rio de Janeiro: Editora FGV, 2005,

Luiz C. Construindo o Estado Republicano: democracia e reforma da gestão pública; tradução: Maria Cristina Godoy. - Rio de Janeiro: Editora FGV, 2009.

BRASIL. Constituição (1988). Constituição da República Federativa do Brasil. Brasília, DF: Senado Federal: Centro Gráfico, 1988.

, Presidência da República (F.H. Cardoso), 1995. Plano Diretor da Reforma do Aparelho do Estado. Brasília: Presidência da República, Câmara da Reforma do Estado. Ministério da Administração Federal e Reforma do Estado.

Plano Diretor da Reforma do Aparelho do Estado. Brasília: Presidência da República, Câmara da Reforma do Estado. Ministério da Administração Federal e Reforma do Estado, 1995

Decreto-Lei n⿳0 200. Dispõe sobre a organização da Administração Pública, estabelece diretrizes para a Reforma Administrativa. Brasília: Presidência da República, 1966.

, Presidência da República. Decreto no 9.690. Altera o Decreto $n^{\circ} 7.724$, de 16 de maio de 2012, que regulamenta a Lei n ${ }^{\circ} 12.527$, de 18 de novembro de 2011 - Lei de Acesso à Informação. 2019.

Presidência da República. Decreto no 9.759. Altera o Decreto $n^{\circ} 7.724$, de 16 de maio de 2012, que regulamenta a Lei n ${ }^{\circ}$ 12.527. Brasília: Presidência da República, 2019 
, Presidência da República. Decreto no 9.812. Altera o Decreto no 9.759 , de 11 de abril de 2019, que extingue e estabelece diretrizes, regras e limitações para colegiados da administração pública federal.

Presidência da República. Lei no 12.527, de 18 de novembro de 2011. Regula o acesso a informações previsto no inciso XXXIII do art. 5o , no inciso II do § 3o do art. 37 e no $§ 2$ o do art. 216 da Constituição Federal; altera a Lei no 8.112, de 11 de dezembro de 1990; revoga a Lei no 11.111, de 5 de maio de 2005, e dispositivos da Lei no 8.159, de 8 de janeiro de 1991; e dá outras providências.

DI PIETRO, Maria Sylvia Zanella. Direito Administrativo. 13. ed. São Paulo: Atlas, 2001.

ESTHER, Rejane. Accountability, Democracia e Cidadania Organizada: Uma análise do conceito de Accountability como ferramenta de Controle e Transparências na Gestão Pública. 2009. Disponível em: http://www.administradores.com.br/artigos/negocios/accountabilitydemocracia-e-cidadania-organizada-uma-analise-do-conceito-de-accountability-comoferramenta-de-controle-e-transparencia-na-gestao-publica/35351. Acesso em: 08 maio 2017.

FAORO, Raymundo. Os donos do Poder: formação do patronato político. $4^{\circ}$ ed. São Paulo: Globo, 2008

FEDERAL. Supremo Tribunal Federal. Ação Direta de Inconstitucionalidade $\mathbf{n}^{0} 6121$. 2019. Disponível em: $<$ http://redir.stf.jus.br/paginadorpub/paginador.jsp?docTP=AC\&docID=375336>. Acesso em 26 ago 2019

HESSEL, Rosana. Mudança na LAI pode prejudicar transparência. 2019. Disponível em: <https://www.em.com.br/app/noticia/economia/2019/01/25/internas_economia,1024395/decre to-de-mourao-prejudica-transparencia-e-acesso-a-informacao.shtml>. Acesso em 26 ago 2019

KEMPFER, Marlene. A democratização da informação e a função social das empresas.In Estudos em Direito Negocial. Org. SOARES, Marcos Antonio Striquer; ARAÚJO JR., Miguel Etinger; MATTOS DO AMARAL, Ana Cláudia Corrêa Zuin. BELLINETTI, Luiz Fernando. Birigui/SP: Boreal, 2016 p. 188-208.

KEMPFER, Marlene; VELOSO, Yslyg Abreu. O regime jurídico das agências reguladoras e sua contribuição para o projeto nacional de desenvolvimento e de cidadania. Brasilia: Anais do XVII Congresso Nacional do CONPEDI. 2008. p. 1168-1182 
KIERECZ, Marlon Silvestre. A crise da democracia representativa no Brasil. Cadernos do Programa de Pós-Graduação em Direito-PPGDir./UFRGS, v. 11, n. 2, 2016

LIDNER, Julia; RIBEIRO, Luci. Derrubado pela Câmara, decreto sobre sigilo de dados é revogado pelo governo. Estadão: 2019. Disponível em: $<$

https://politica.estadao.com.br/noticias/geral,derrubado-pela-camara-decreto-sobre-sigilo-dedados-e-revogado-pelo-governo,70002737500>. Acesso em: 01 set. 2019

MARQUES NETO, Floriano Peixoto de Azevedo. Regulação Estatal e Interesses Públicos. São Paulo: Malheiros, 2002.

OSBORNE, David; GAEBLER, Ted. Reinventando o governo: como o espírito empreendedor está transformando o setor público. Brasília: M.H. Comunicação, 1992.

PONTES, Felipe. STF limita decreto do governo que extingue conselhos fiscais. EBC: Agencia brasil. 2019. Disponível em: <http://agenciabrasil.ebc.com.br/justica/noticia/201906/stf-limita-decreto-do-governo-que-extingue-conselhos-federais>. Acesso em 01 set. 2019

RAMOS, Cesar Augusto. O modelo liberal e republicano de liberdade: uma escolha disjuntiva? Transformação, v. 34, n 1, p. 43-66, 2011.

SILVA, Cláudio Eduardo Regis de Figueiredo. Administração Gerencial e A Reforma Administrativa no Brasil. Curitiba: Juruá, 2004. 226 p.

STF, Supremo Tribunal Federal. STF inicia julgamento de ação contra extinção por decreto de conselhos federais da administração pública. 2019. Disponível em:<

http://www.stf.jus.br/portal/cms/verNoticiaDetalhe.asp?idConteudo=413839\#> Acesso em: 01 set. 2019

VILELA, Maria Diogenilda de Almeida. Legislação que disciplina os conselhos de políticas públicas. Câmara dos Deputados: Consultoria Legislativa. 2005. Disponível em: < https://www2.camara.leg.br/atividade-legislativa/estudos-e-notas-tecnicas/publicacoes-daconsultoria-legislativa/areas-da-conle/tema6/2005_740.pdf> Acesso em: 01 set. 2019

WOLKMER, Antonio Carlos. Do paradigma político da representação à democracia participativa. Seqüência: estudos jurídicos e políticos, v. 22, n. 42, p. 83-98, 2001. 